Supplement of Earth Syst. Dynam., 11, 97-111, 2020

https://doi.org/10.5194/esd-11-97-2020-supplement

(C) Author(s) 2020. This work is distributed under

the Creative Commons Attribution 4.0 License.

(c) (i)

Supplement of

\title{
Amplified warming of seasonal cold extremes relative to the mean in the Northern Hemisphere extratropics
}

Mia H. Gross et al.

Correspondence to: Mia H. Gross (mia.gross89@gmail.com)

The copyright of individual parts of the supplement might differ from the CC BY 4.0 License. 
CanESM2 ensemble runs - future excess changes

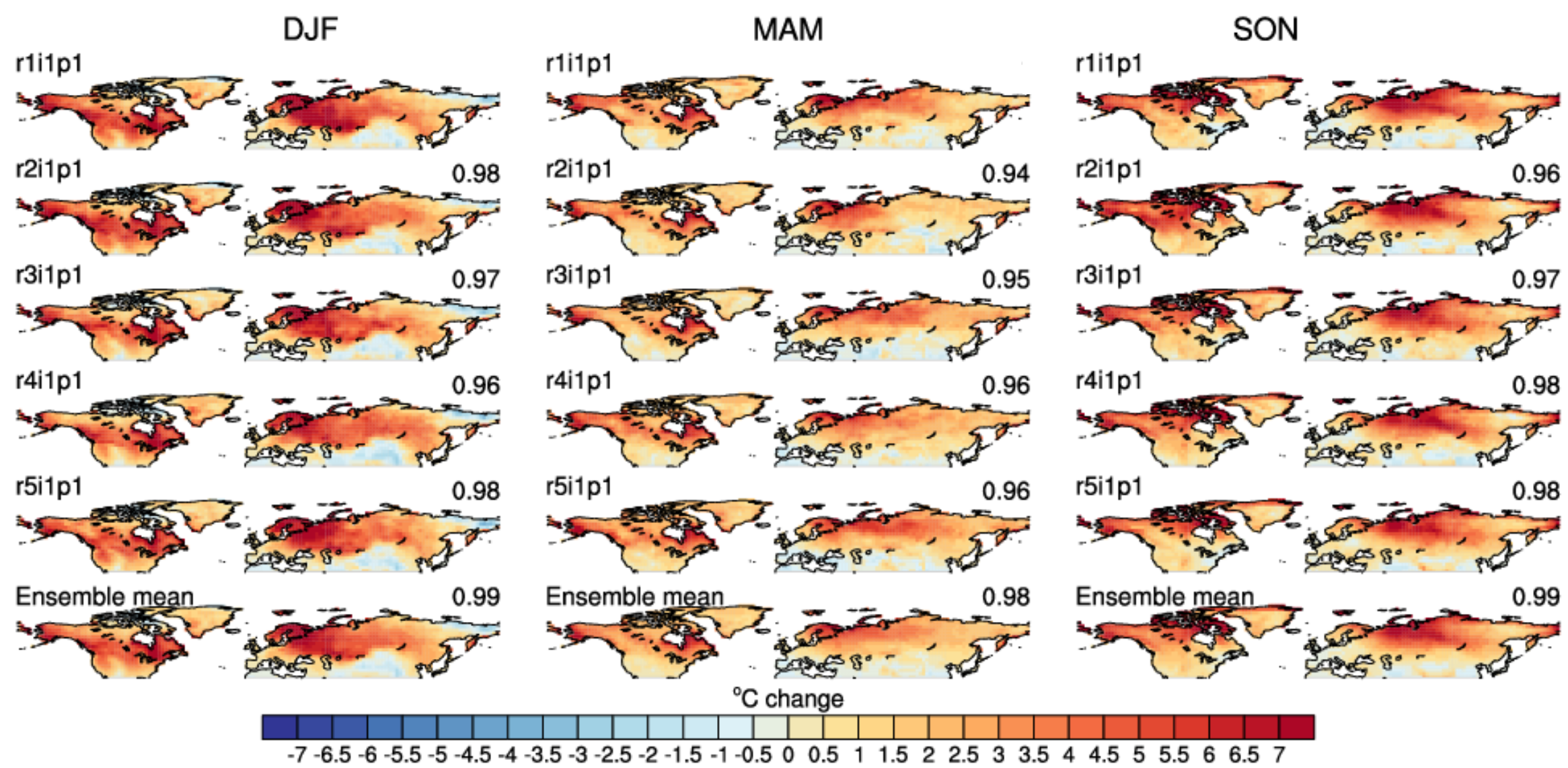

Figure S1: Example of multiple ensemble runs in the CanESM2 ensemble for boreal winter (left column), spring (middle column) and autumn (right column), as shown for future excess changes (see Fig. 3 for results of future excess changes). Numbers in the top right of each panel show the pattern correlation with the r1i1p1 run (top row). The ensemble mean for each season is shown in the bottom row. 
Future excess changes in cold extremes (2070-2099 - 1950-1979)

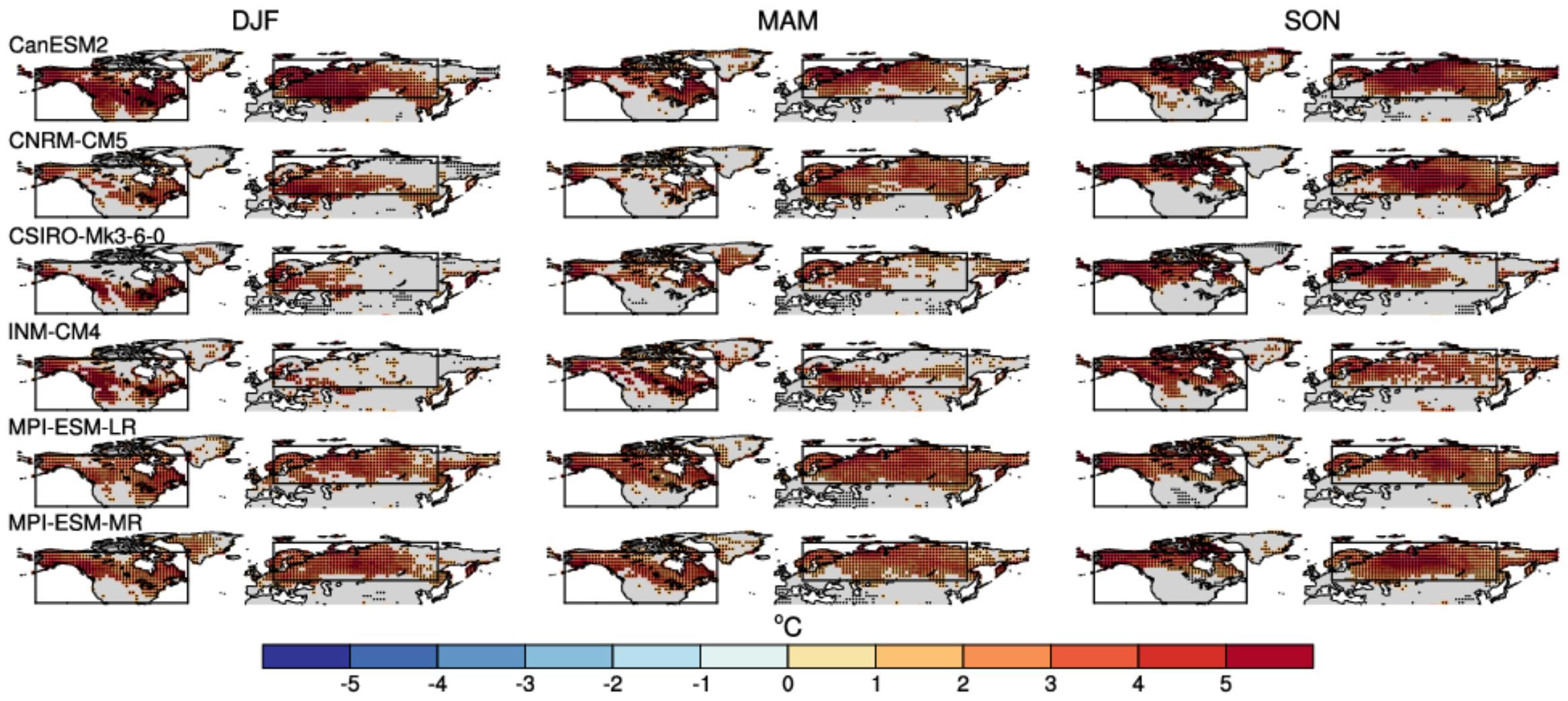

Figure S2: Boxed regions used for calculating area-averages for the scatter plots and correlations in Figs. 4-5. Two regions are used: North America and northern Eurasia. The criteria specifies to only include grid cells which are both significant and that have future excess changes exceeding $1^{\circ} \mathrm{C}$. 

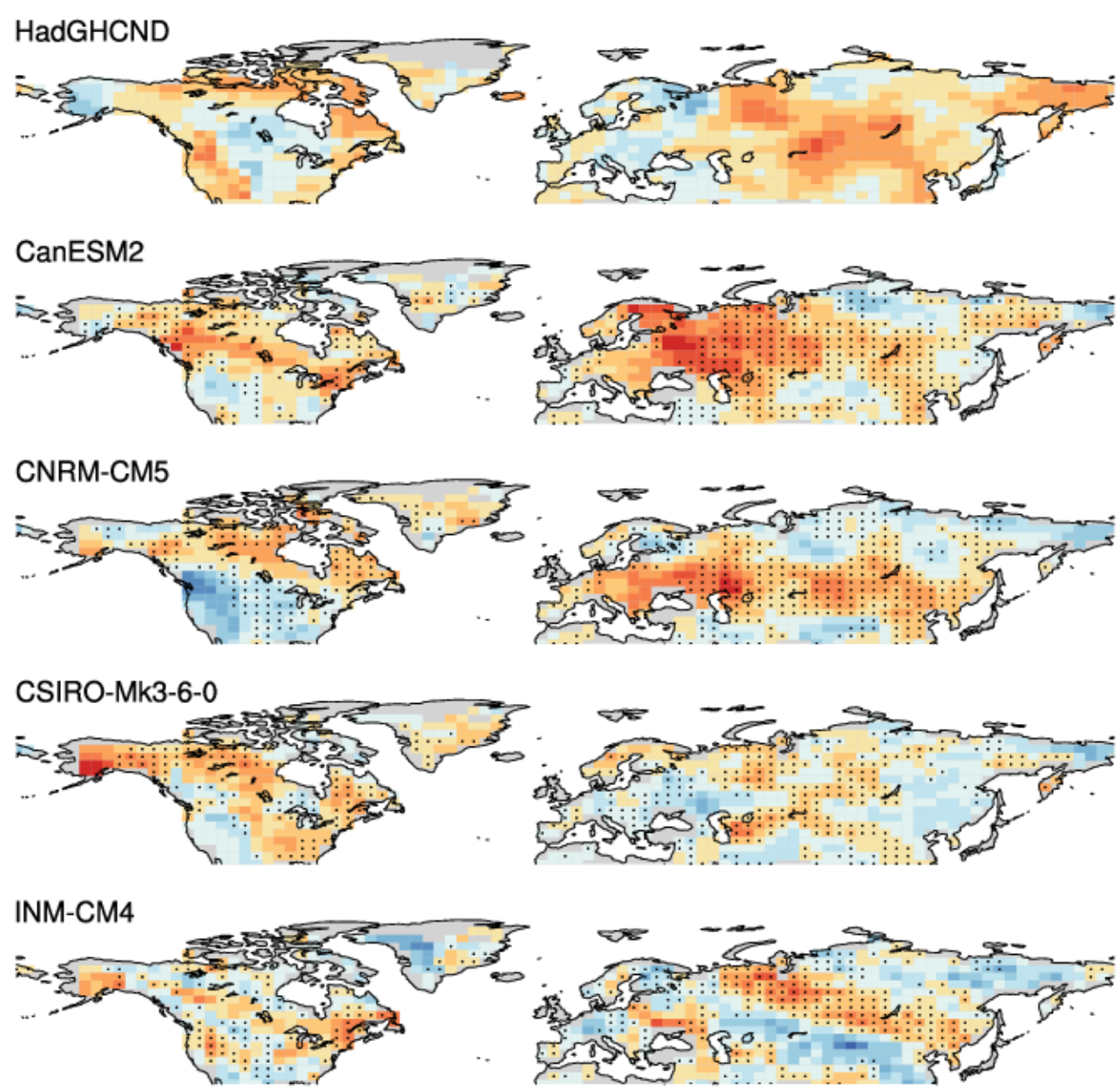

MPI-ESM-LR
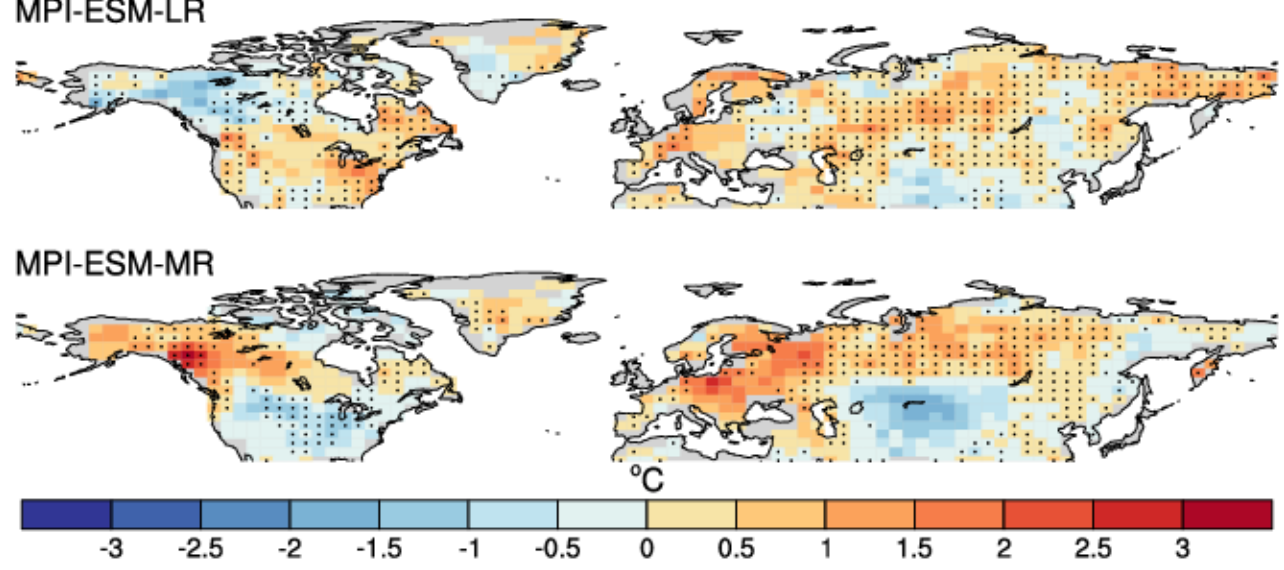

Figure S3: Recent excess changes (1982-2014 - 1950-1981) in cold extremes (seasonal minima - seasonal mean) for boreal winter (DJF) in HadGHCND and the six individual CMIP5 models used to calculate the multi-model mean in Figure 1. Grey areas represent areas where data is missing in HadGHCND. Stippling in the models represents grid cells that agree in sign with HadGHCND. 

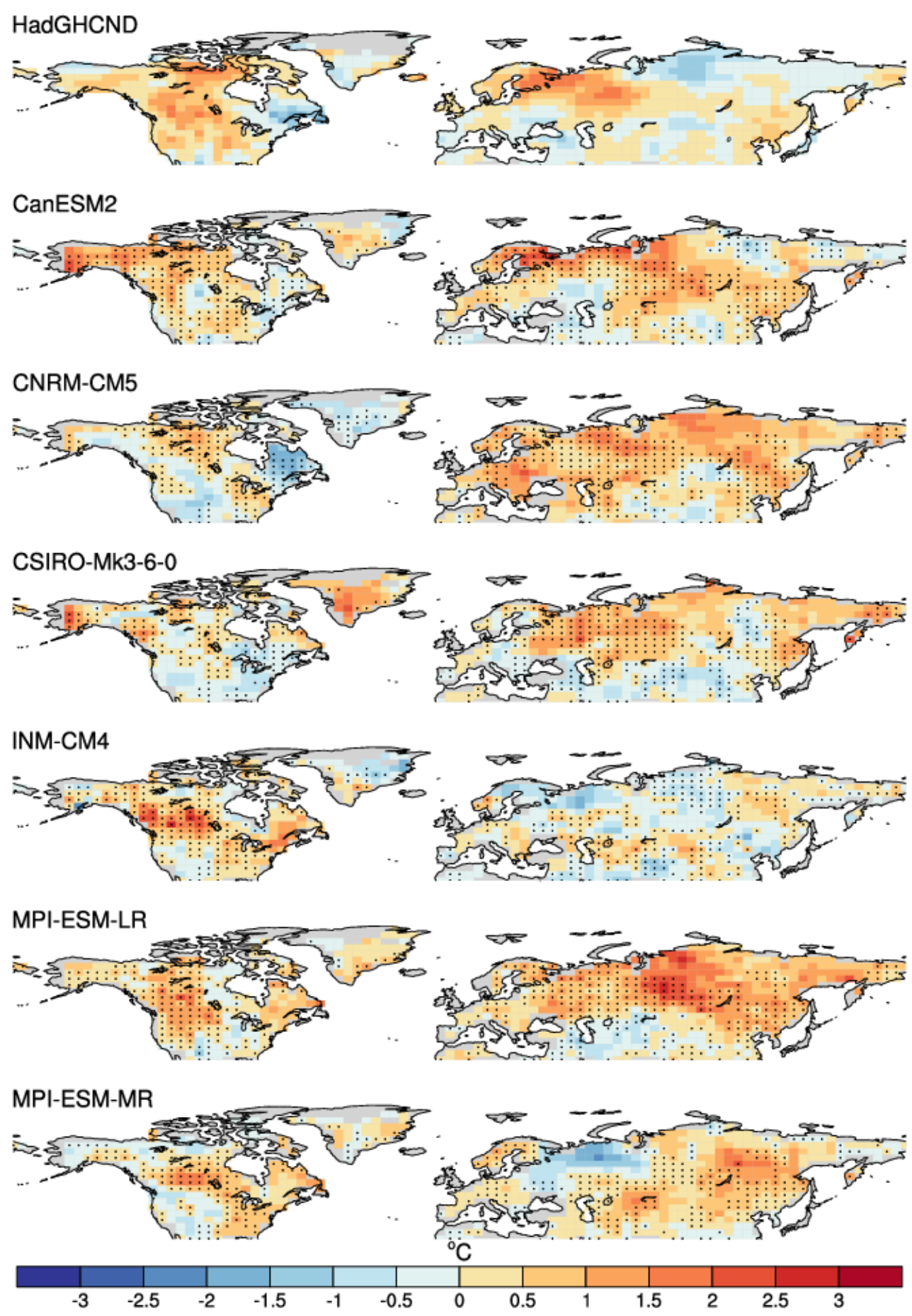

Figure S4: As Fig. S3, but for boreal spring (MAM). 

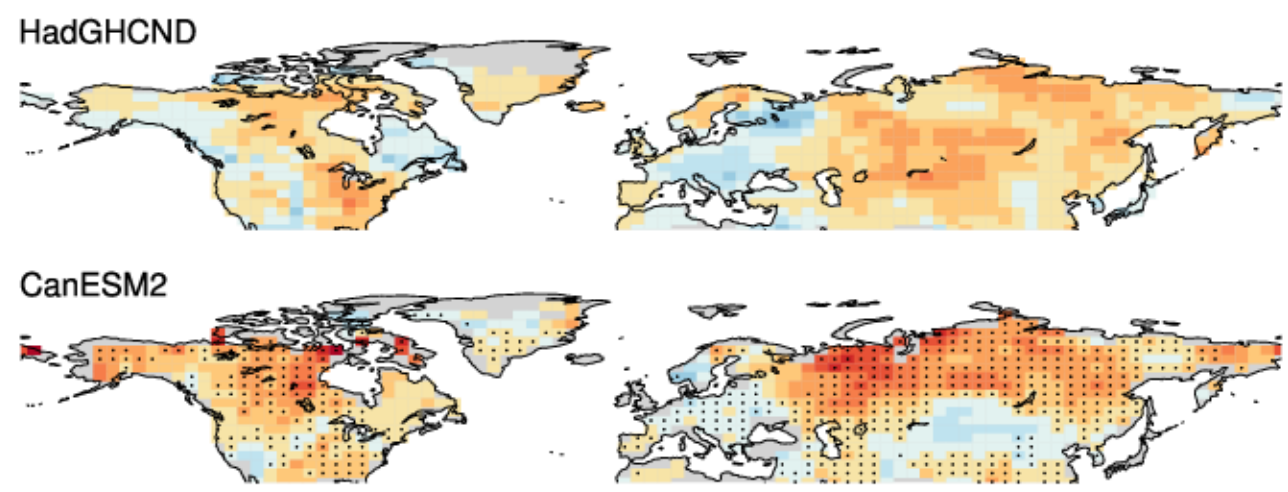

CNRM-CM5
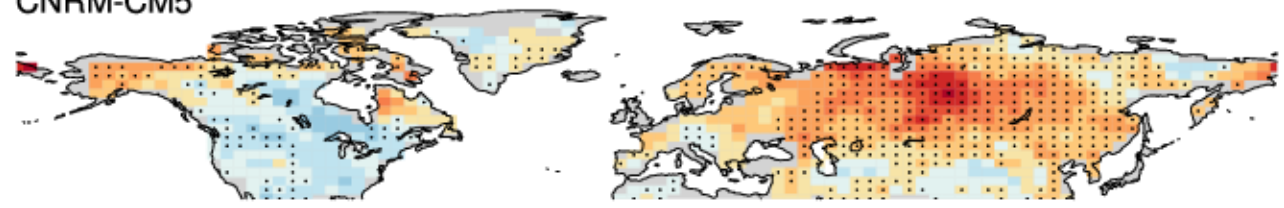

CSIRO-Mk3-6-0
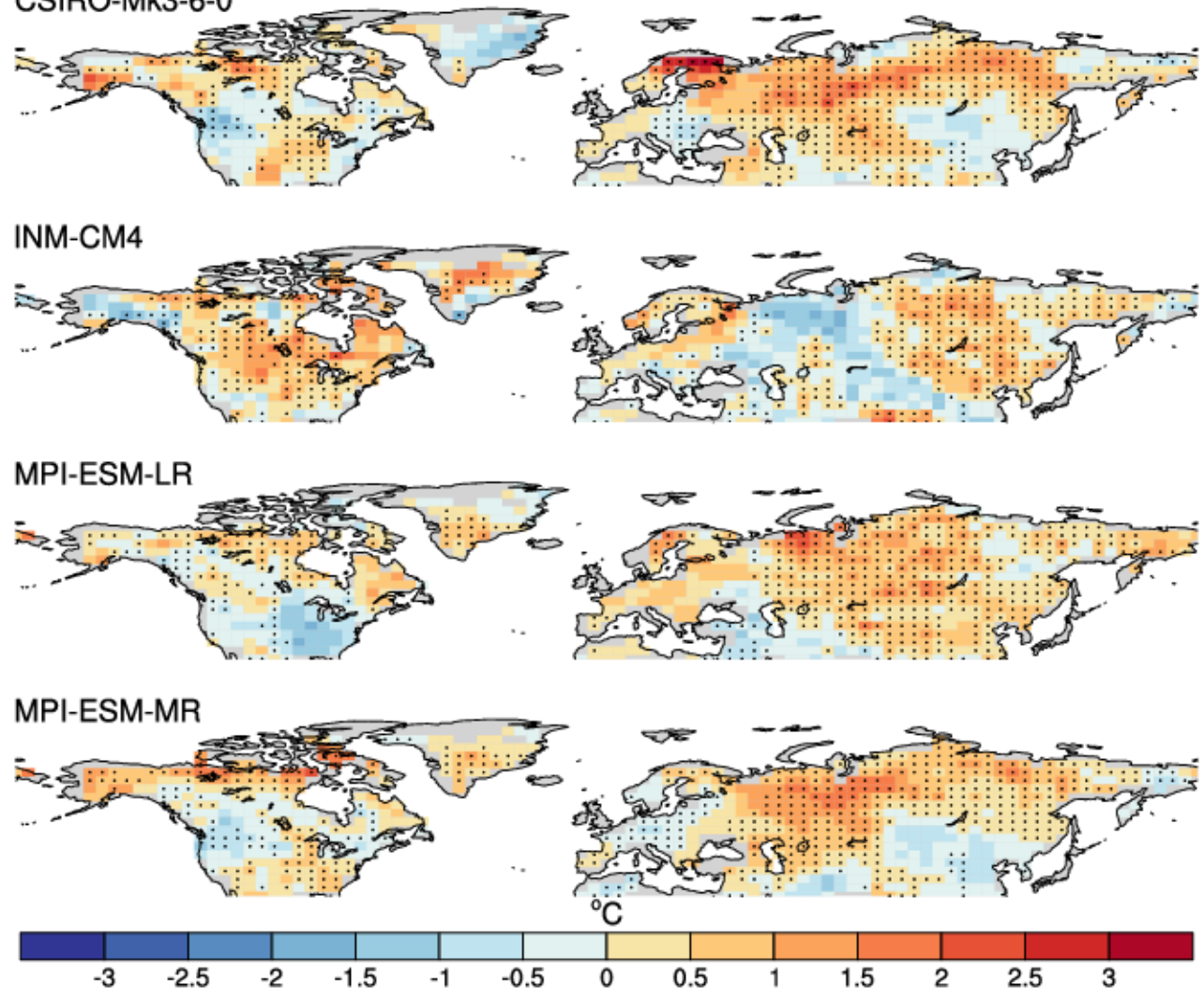

Figure S5: As Fig. S3, but for boreal autumn (SON). 

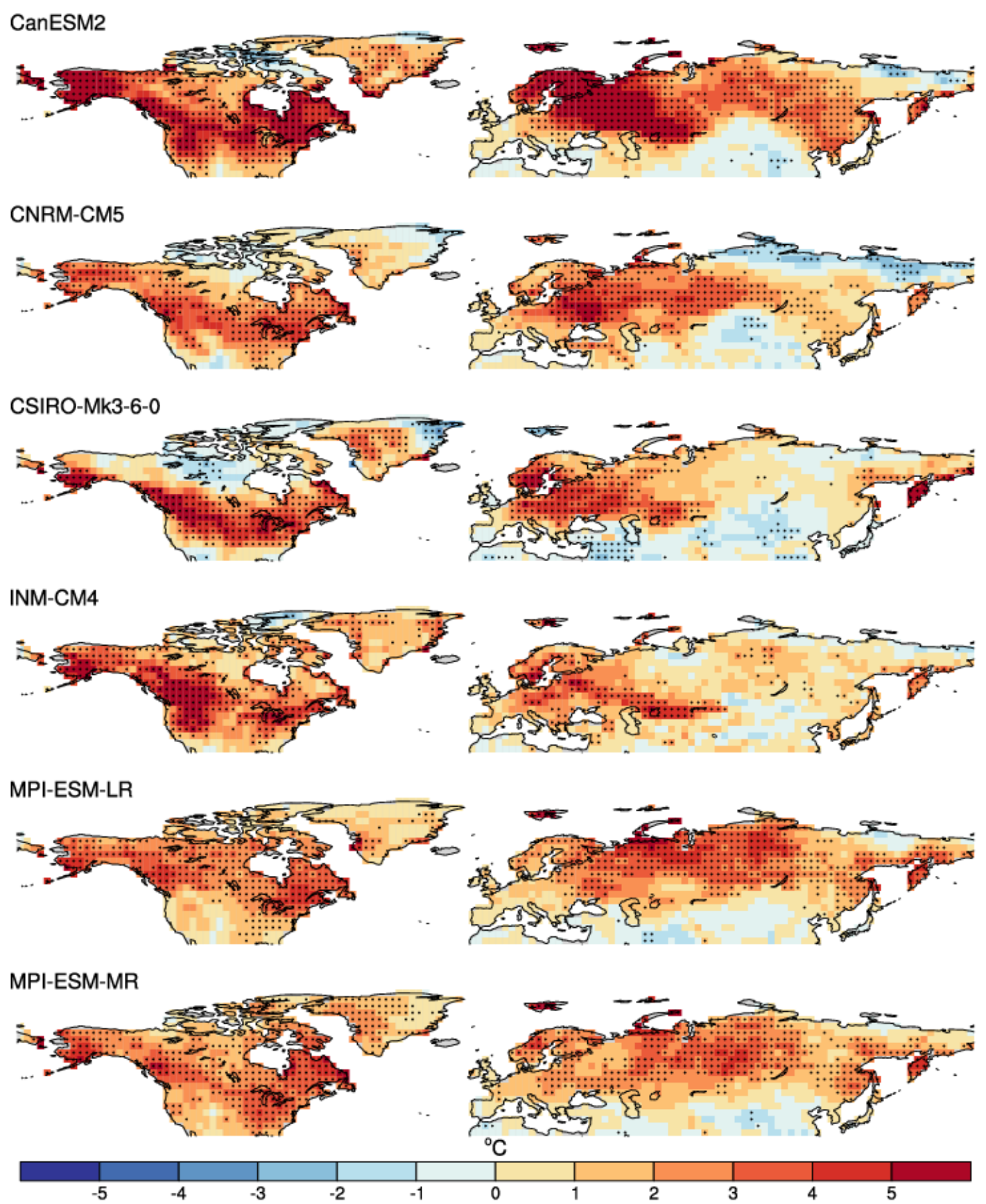

Figure S6: Future excess changes (2070-2099 - 1950-1979) in cold extremes (seasonal minima - seasonal mean) for boreal winter (DJF) in the six individual CMIP5 models used to calculate the multi-model mean shown in Fig. 2. Stippling in the models represents grid cells that are significant at the $5 \%$ level as assessed by a KS-test. 

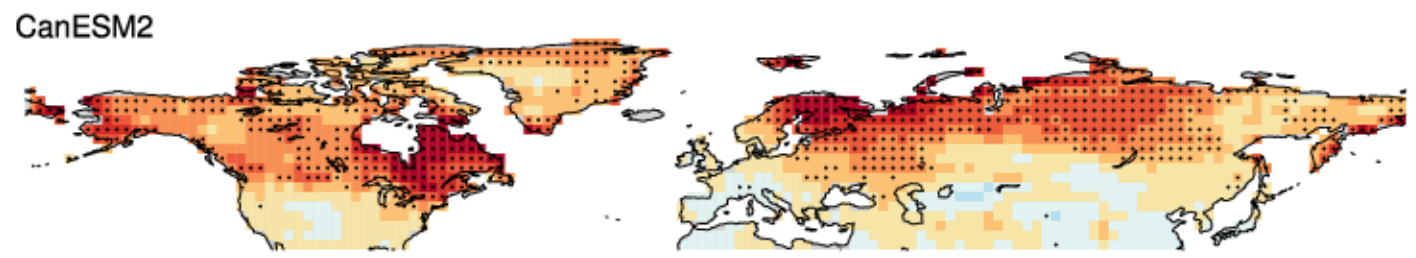

CNRM-CM5
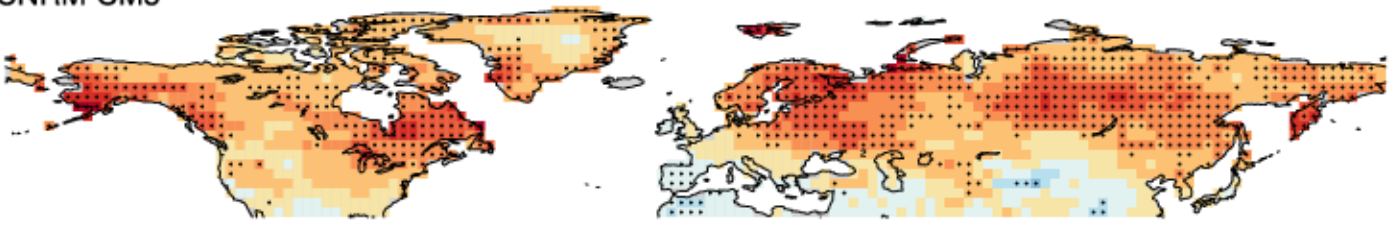

CSIRO-Mk3-6-0
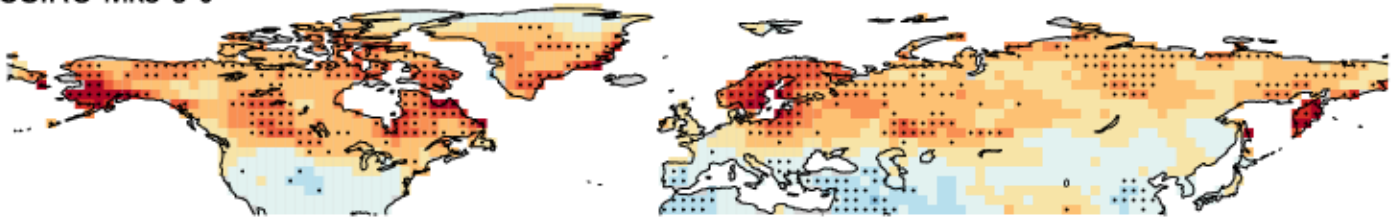

INM-CM4
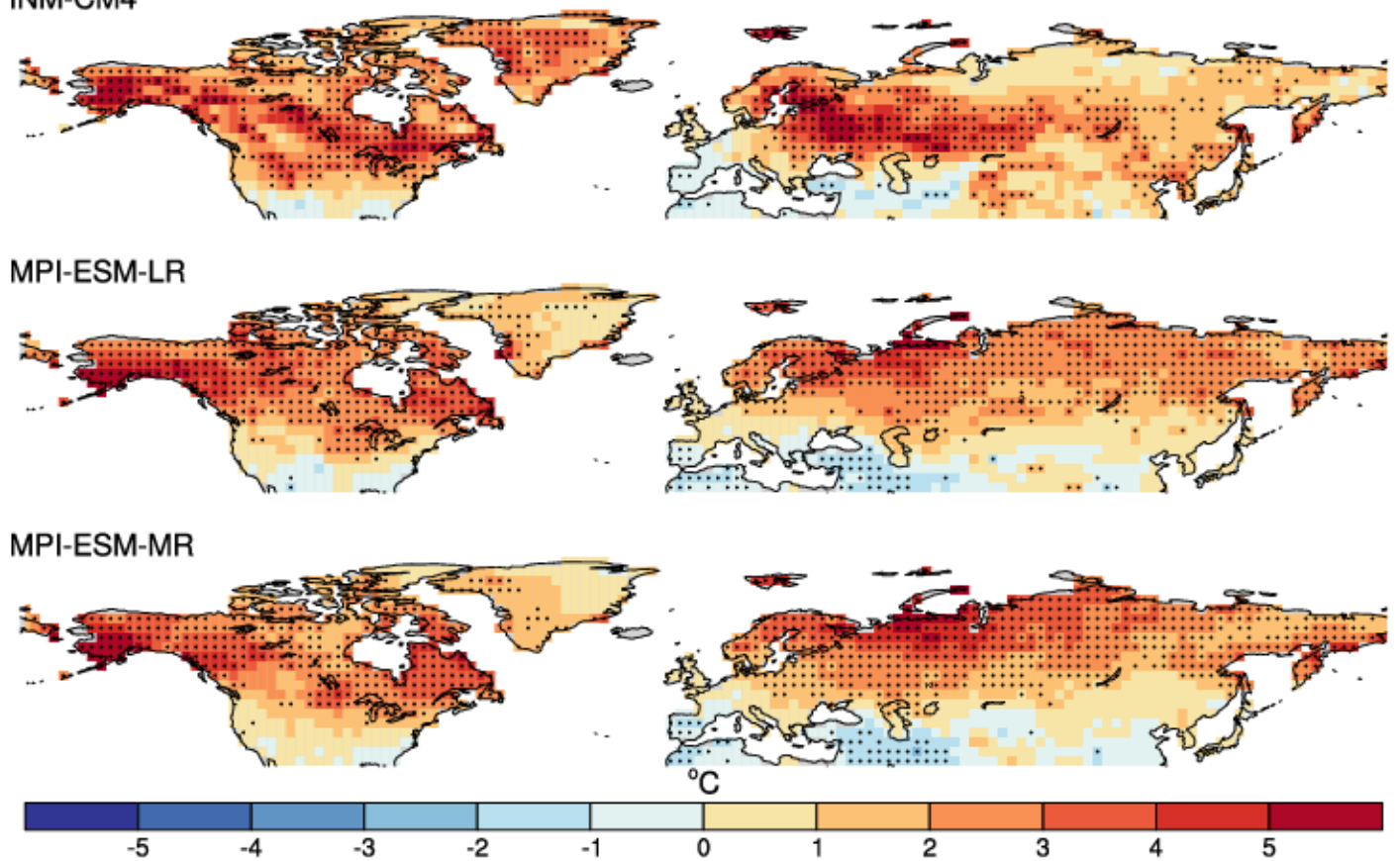

Figure S7: As Fig. S6, but for boreal spring (MAM). 

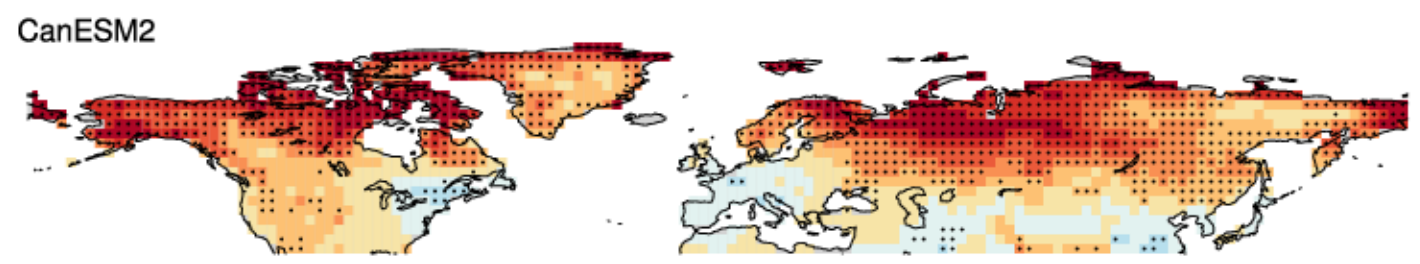

CNRM-CM5
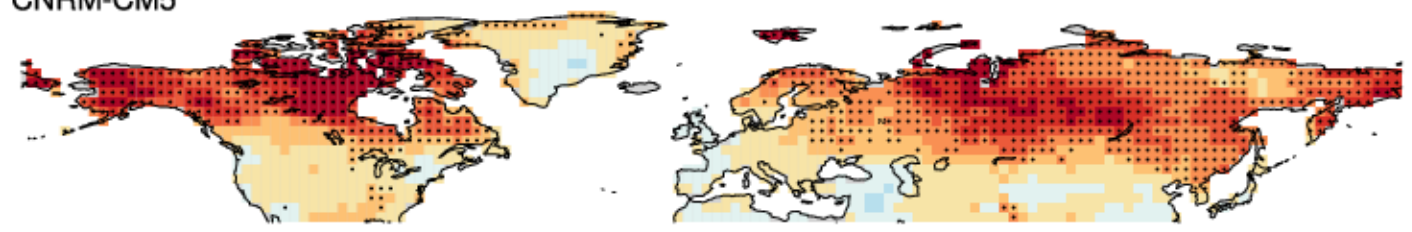

\section{CSIRO-Mk3-6-0}
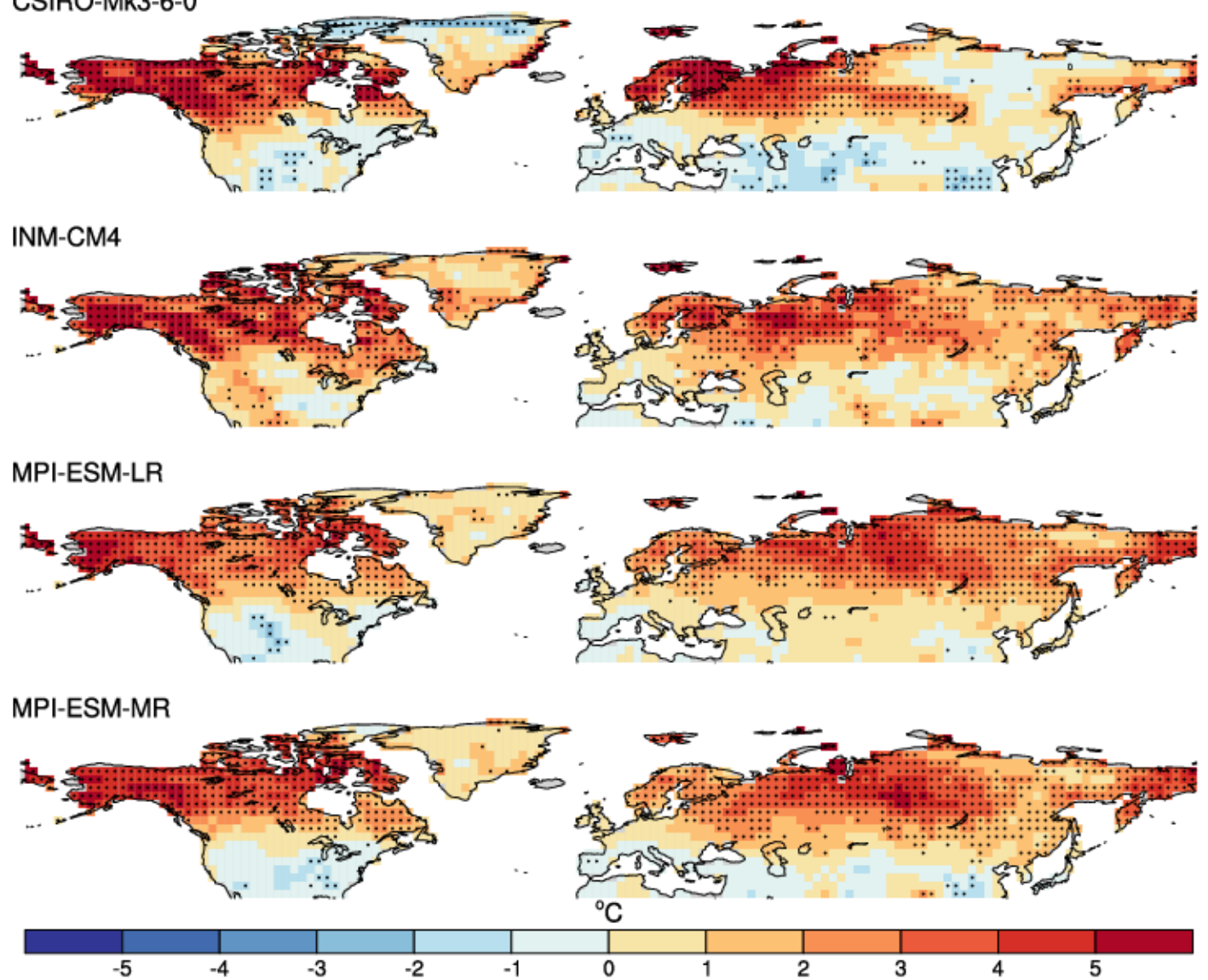

Figure S8: As Fig. S6, but for boreal autumn (SON). 
Future changes in temperature advection (3 day average prior to day of extreme)

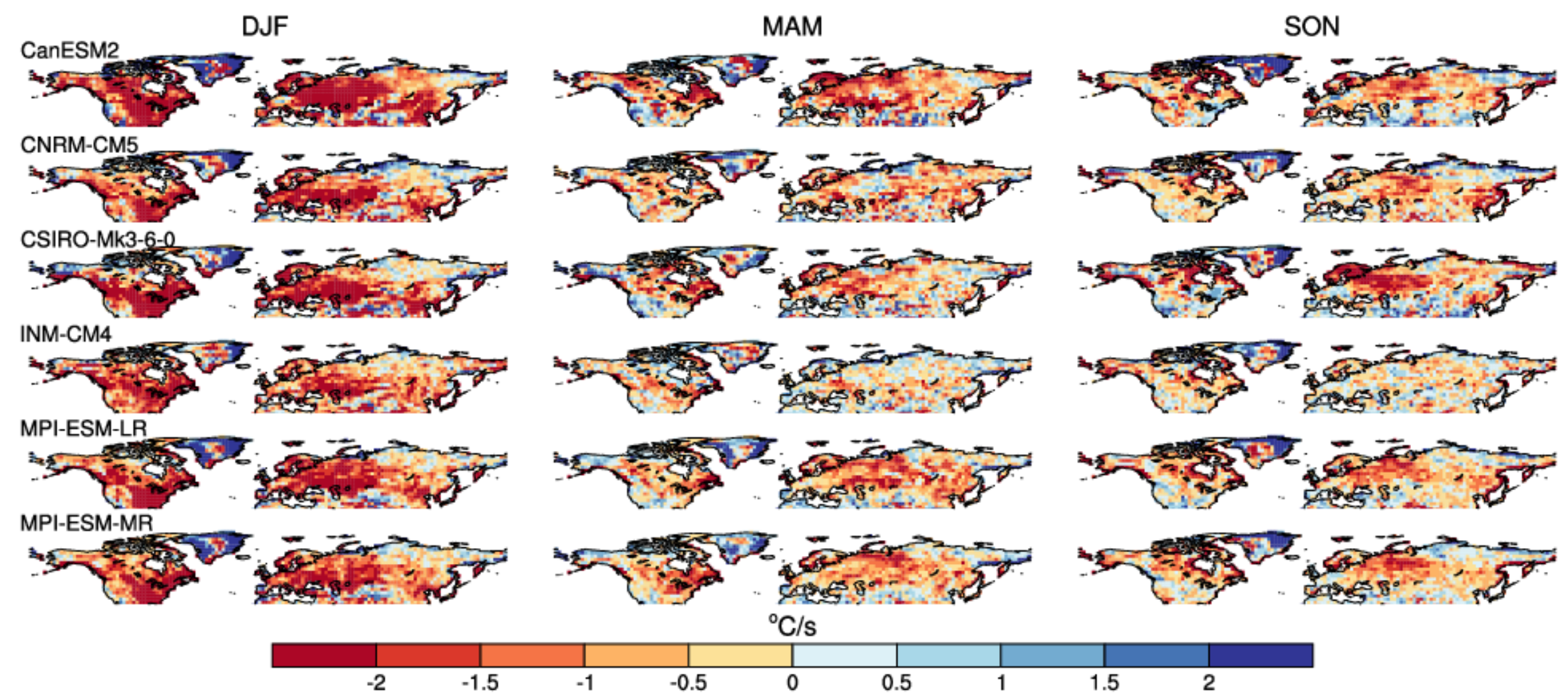

Figure S9: Future changes (2070-2099 - 1950-1979) in temperature advection, where negative values indicate grid cells where advection of cold air is projected to decrease, and positive values indicate grid cells where advection of cold air is projected to increase. Changes are calculated using the average values of the three days prior to the day the seasonal minimum occurs. 
Future excess changes in temperature advection ( 3 day average prior to day of extreme)

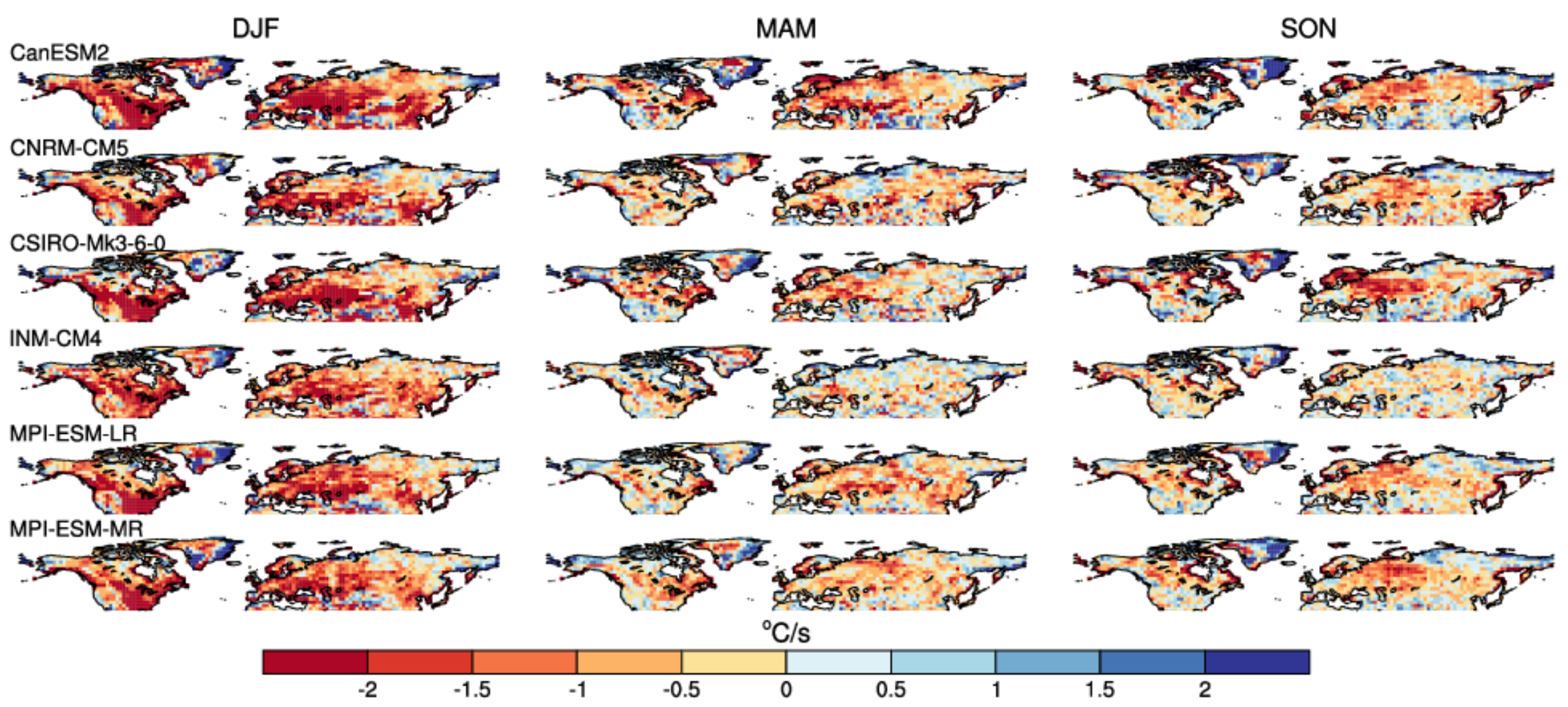

Figure S10: As Fig. S9, but for excess temperature advection (i.e. average of three days prior to the day the seasonal minimum occurs seasonal average temperature advection). 


\section{Future changes in snow cover (on day of extreme)}

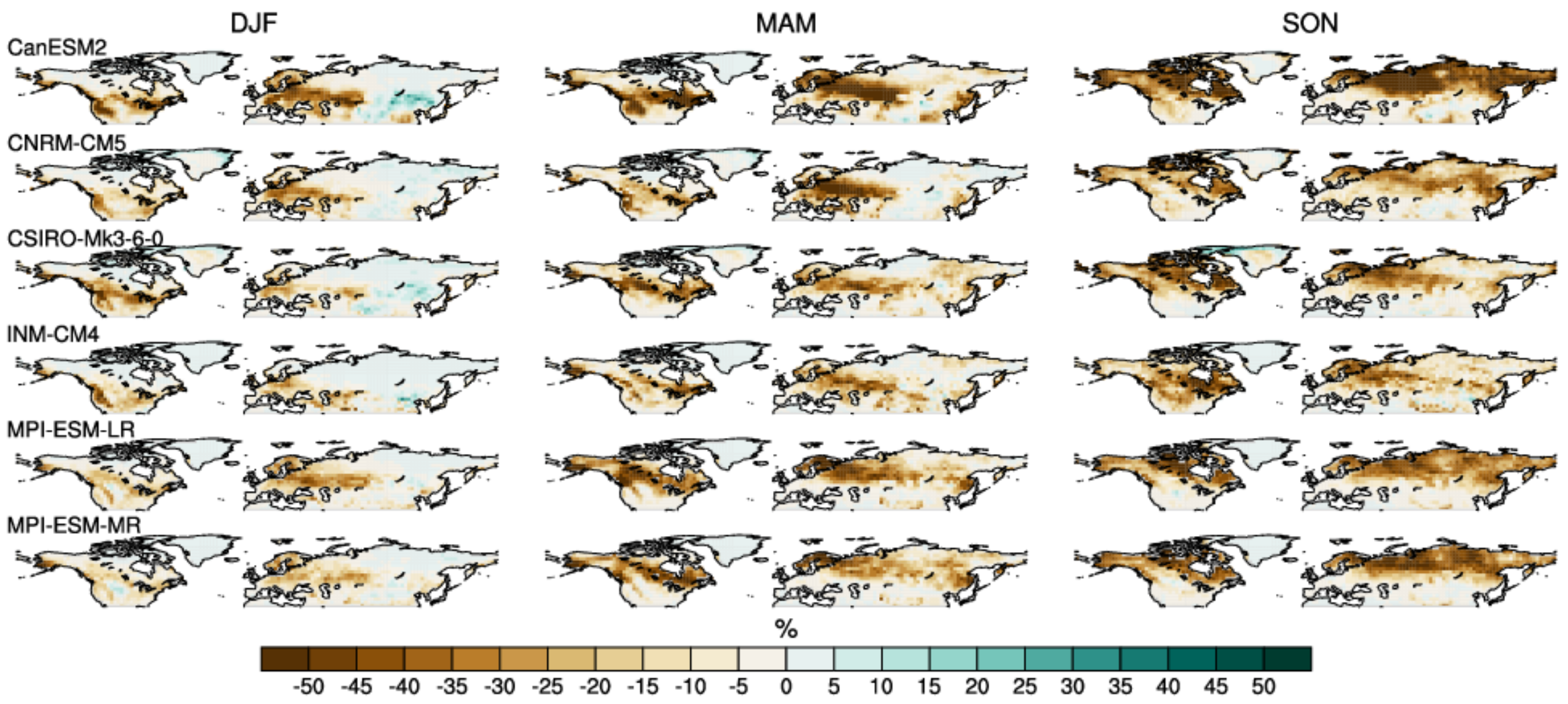

Figure S11: As Fig. S9, but for future changes in actual snow cover, calculated using values of snow cover for the day the seasonal minimum occurs only. 
Future excess changes in snow cover (on day of extreme)

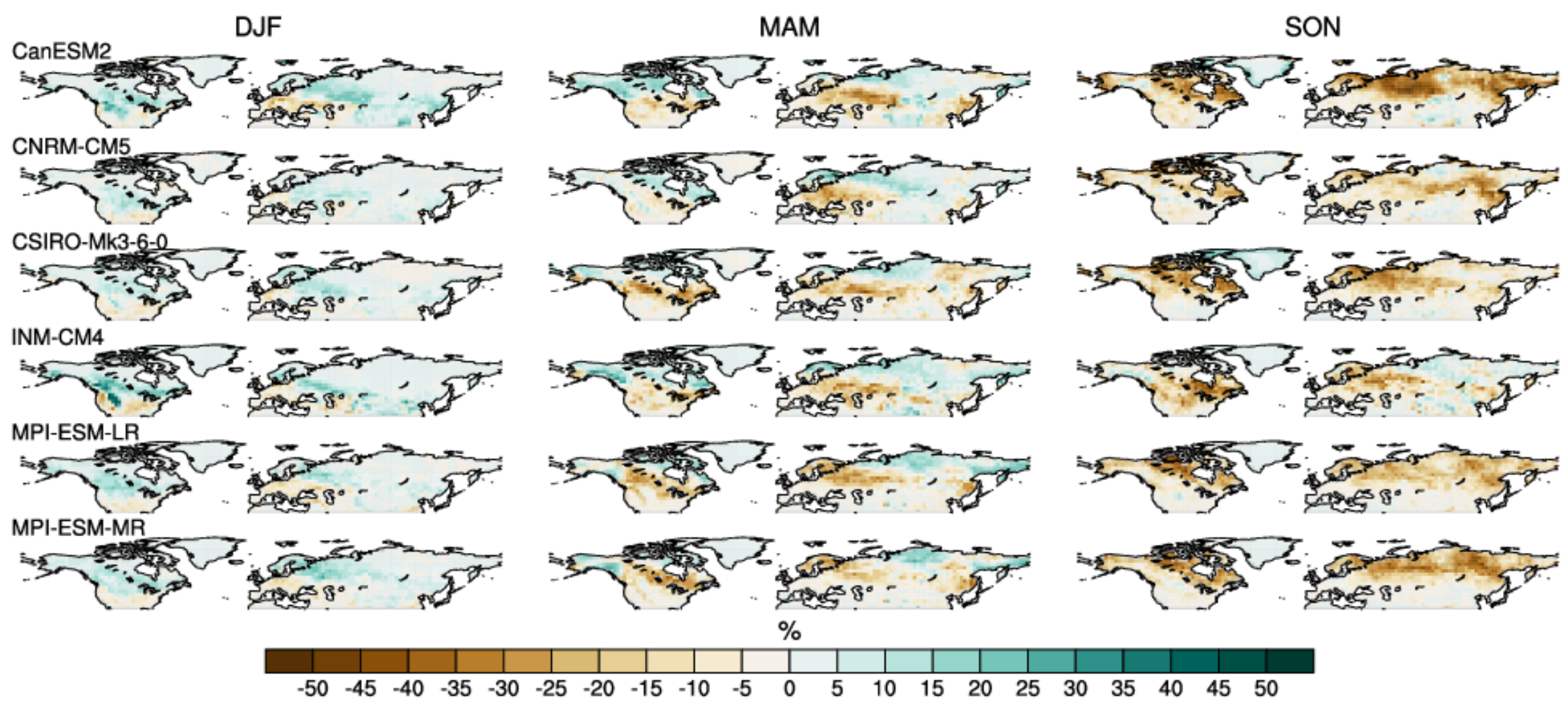

Figure S12: As Fig. S11, but for excess snow cover. 
Future changes in albedo (on day of extreme)

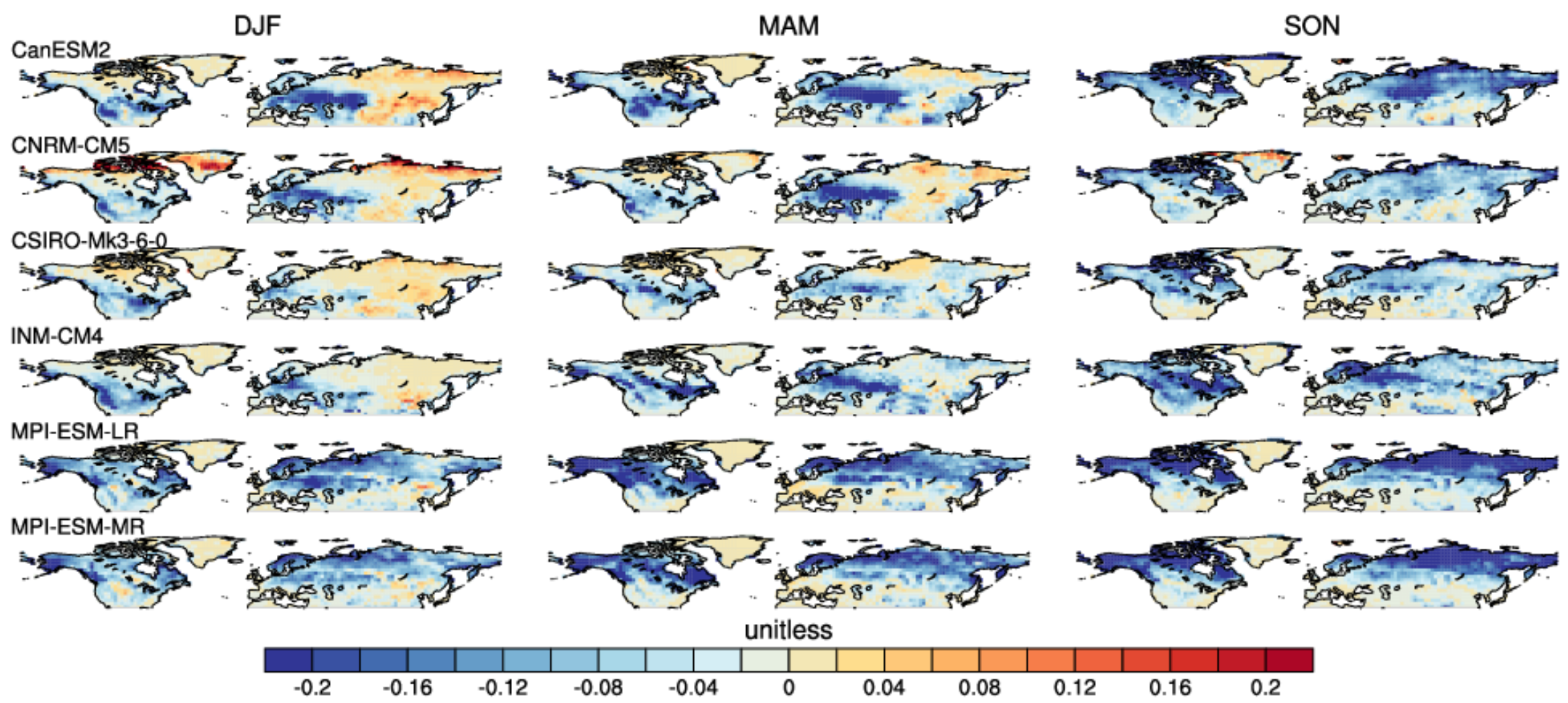

Figure S13: As Fig. S9, but for surface albedo. 
Future excess changes in albedo (on day of extreme)

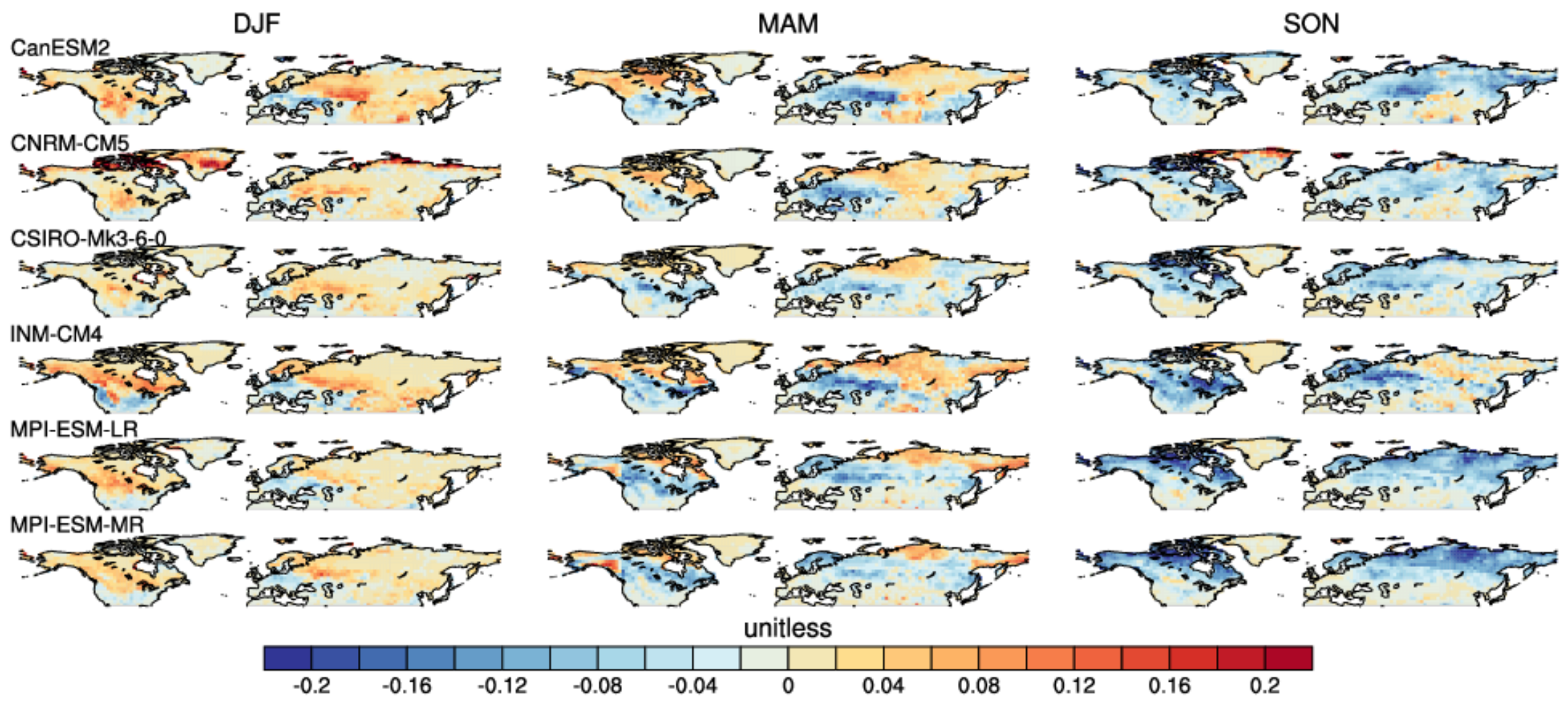

Figure S14: As Fig. S13, but for excess surface albedo. 
Future changes in snow amount (on day of extreme)

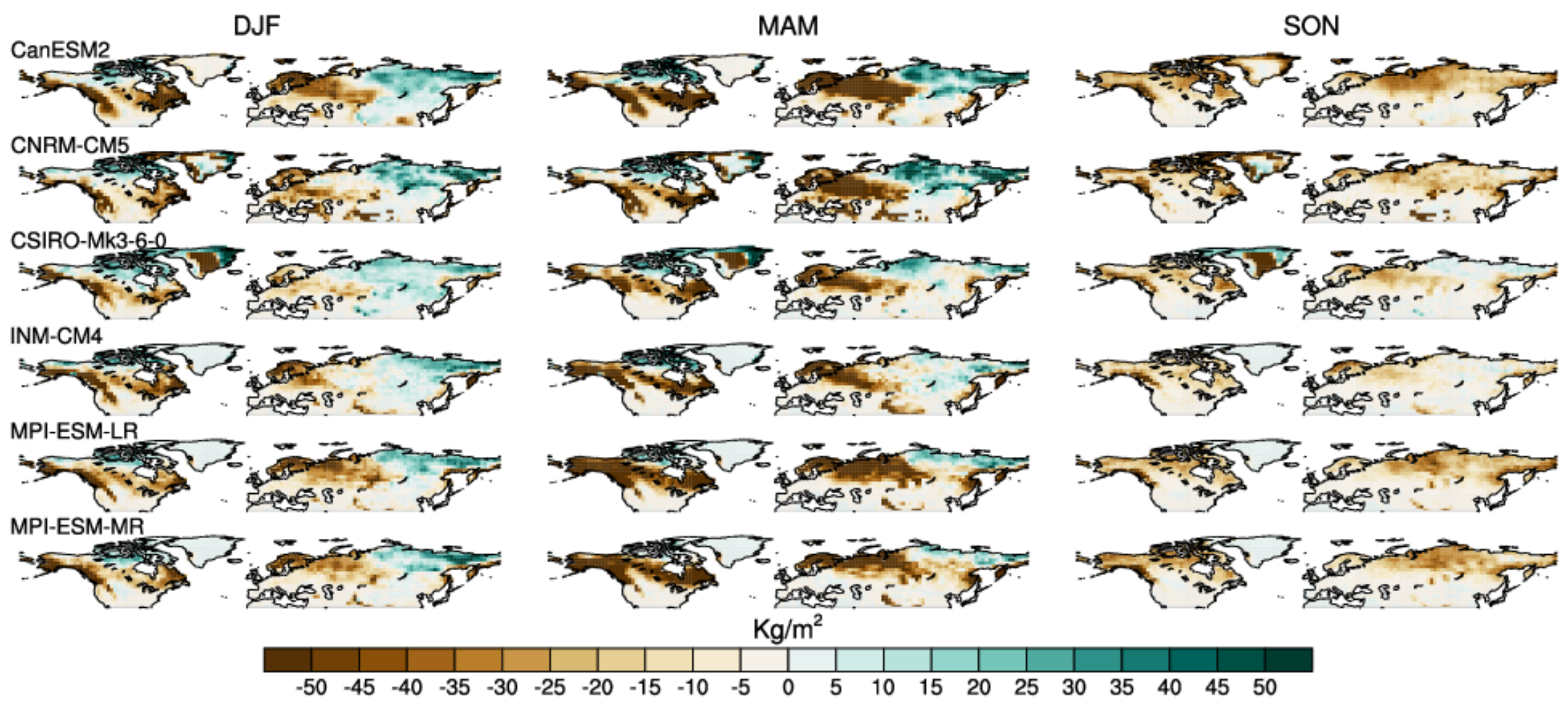

Figure S15: As Fig. S9, but for actual snow amount. 
Future excess changes in snow amount (on day of extreme)

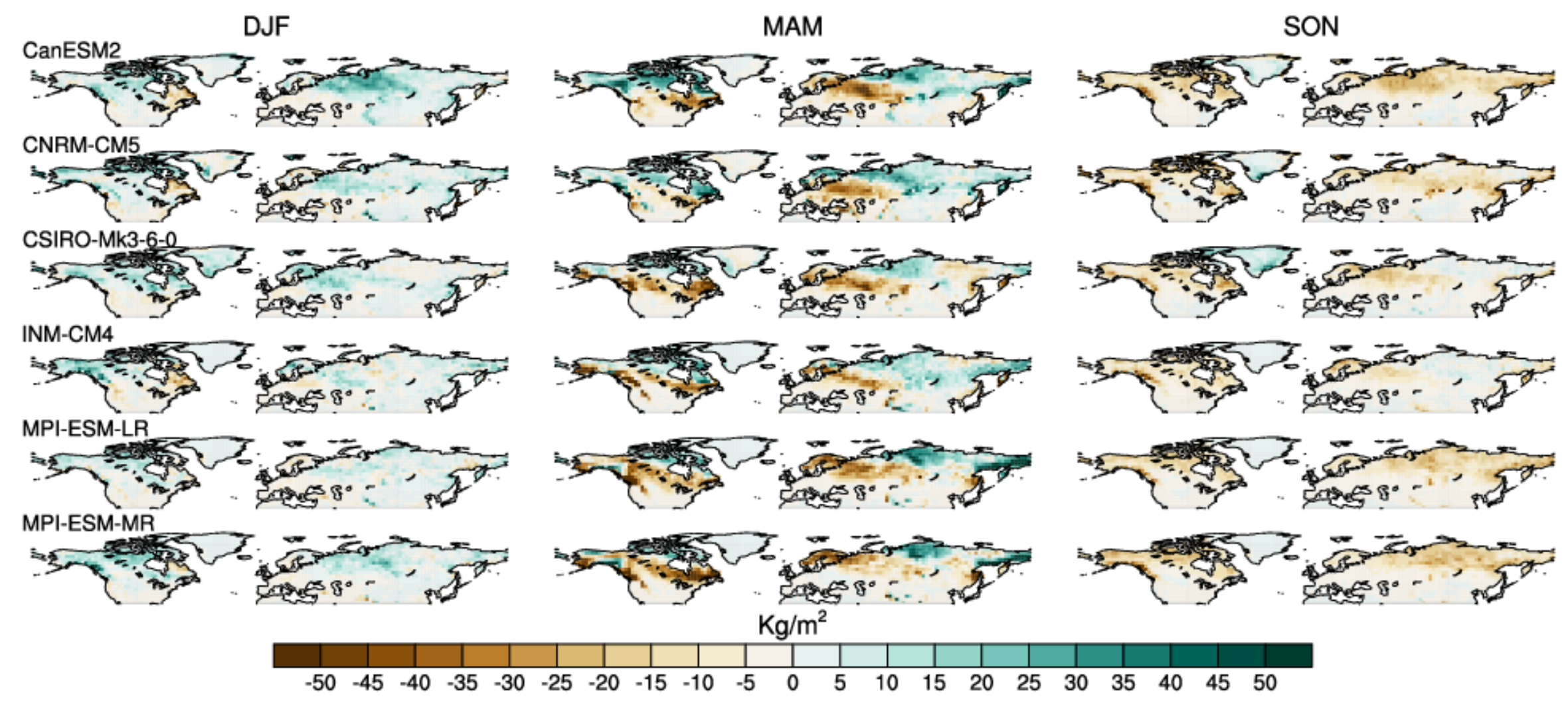

Figure S16: As Fig. S15, but for excess snow amount. 
Future changes in the timing of anomalously cold days

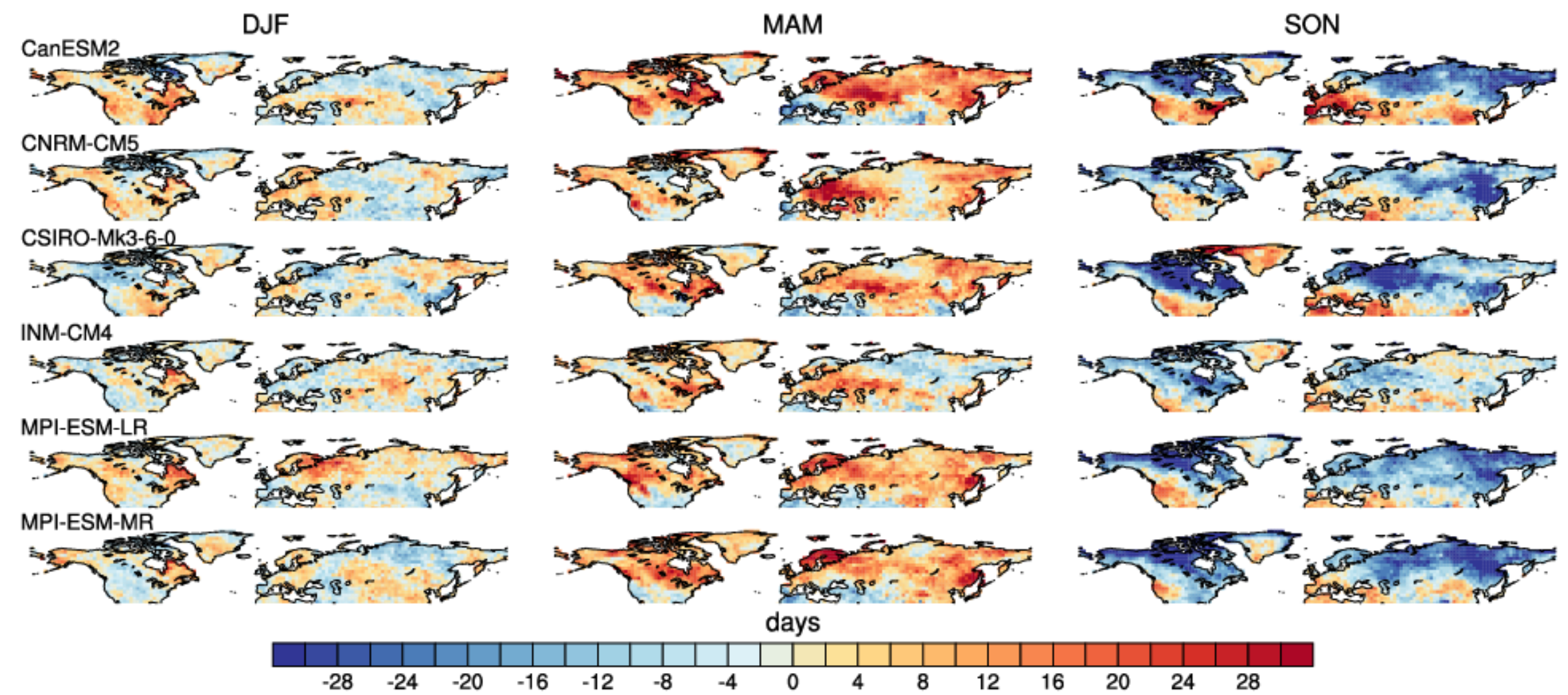

Figure S17: Future changes in the timing of the anomalously coldest days in the season for boreal winter (left column), spring (middle column) and autumn (right column) in the six individual CMIP5 models used to calculate the multi-model mean shown in Fig. 6 . Negative values indicate grid cells where cold extremes are projected to occur earlier in the season, positive values show where cold extremes are projected to occur later in the season. 